\title{
Morfologia externa dos estágios imaturos de heliconíneos neotropicais: IV. Dryas iulia alcionea (Lepidoptera, Nymphalidae, Heliconiinae) ${ }^{1}$
}

\author{
Antonio C. Paim²; Lucas A. Kaminski² \& Gilson R. P. Moreira ${ }^{2}$ \\ 1. Contribuição $n^{\circ} 413$ do Departamento de Zoologia, Universidade Federal do Rio Grande do Sul (UFRGS). \\ 2. Departamento de Zoologia, Instituto de Biociências, UFRGS, Av. Bento Gonçalves, 9500; 91501-970, Porto Alegre, RS, Brasil. \\ (gilson.moreira@ufrgs.br)
}

\begin{abstract}
External morphology of the immature stages of neotropical heliconians: IV. Dryas iulia alcionea (Lepidoptera, Nymphalidae, Heliconiinae). The external features of egg, larva and pupa of Dryas iulia alcionea (Cramer, 1779) are described and illustrated.
\end{abstract}

KEYWORDS. Heliconiinae, immature stages, Lepidoptera, morphology, Nymphalidae.

\section{INTRODUÇÃO}

Dryas iulia (Fabricius, 1775) distribui-se do sul dos Estados Unidos ao norte do Uruguai e Argentina (EMSLEY, 1963; DE VRIES, 1987). Doze subespécies são reconhecidas por EMSLey (1963), as quais diferem pela coloração de fundo nas asas, intensidade e extensão das manchas negras correspondentes e distribuição das androcônias nas asas anteriores dos machos. Segundo Brown (1992) e BRown \& YePEZ (1984), as populações continentais sulamericanas correspondem predominantemente a Dryas iulia alcionea (Cramer, 1779). Esta subespécie é encontrada nos mais variados hábitats, predominantemente naqueles perturbados. Embora suas larvas utilizem diversas passifloráceas como plantas hospedeiras, são encontradas preponderantemente sobre aquelas do subgênero Plectostemma Masters (Brown \& Mielke, 1972; Benson et al., 1976; Périco \& AraúJo, 1991; Brown, 1992).

BEEBE et al. (1960) ilustraram o ovo, a larva e a pupa de D. iulia, entre outras espécies de heliconíneos. FLEMING (1960) caracterizou a larva de primeiro instar quanto à morfologia genérica e quetotaxia. Tais trabalhos foram realizados em Trinidad e referem-se a Dryas iulia iulia (Fabricius, 1775) (EMSLEY, 1963). A utilização de caracteres morfológicos ultra-estruturais tem grande significado na compreensão da filogenia deste grupo, principalmente quando unidos a estudos com base na biologia molecular (LeE et al., 1992; BROWER \& EGAN, 1997; Penz, 1999). No entanto, a morfologia ultra-estrutural da maioria das espécies de heliconíneos não foi ainda abordada. O objetivo é descrever e ilustrar a ultraestrutura dos estágios imaturos de D. iulia alcionea, bem como a quetotaxia da larva e identificar morfometricamente os respectivos ínstares.

\section{MATERIAL E MÉTODOS}

Ovos e larvas de D. iulia alcionea foram coletados sobre Passiflora suberosa L. nos arredores de Porto Alegre, Rio Grande do Sul. Ramos com ovos foram transportados ao laboratório e inseridos em garrafas plásticas contendo água, para o desenvolvimento embrionário e obtenção de larvas e pupas. As análises tiveram como base 20 ovos, 96 larvas e 20 pupas, que foram fixados em solução de Dietrich, e conservados em etanol $70 \%$. O material examinado encontra-se depositado sob os números 113 e 114, na coleção do Laboratório de Morfologia e Comportamento de Insetos (LMCI), Departamento de Zoologia, UFRGS, Porto Alegre, Rio Grande do Sul, Brasil.

As cápsulas cefálicas foram reidratadas e posteriormente clarificadas em $\mathrm{KOH} 10 \%$ e montadas sobre lâmina/lamínula, com gelatina glicerinada como meio de inclusão. As análises microscópicas, medidas e ilustrações para todos os ínstares foram realizadas para um número superior a 16 exemplares. O padrão de coloração da larva de quinto instar e da pupa foi representado utilizando-se a técnica de aquarela em papel Fibronati e da observação de espécimes vivos. Para a identificação dos ínstares, as medidas da maior largura da cápsula cefálica, em vista frontal, foram realizadas em larvas preservadas. Os valores relativos foram ajustados pelo método dos mínimos quadrados à função $\mathrm{y}=\mathrm{ae}^{\mathrm{bx}}$ (Snedecor \& Cochran, 1980). Para a análise em microscopia eletrônica de varredura os espécimes foram desidratados em ponto crítico e montados em suporte de alumínio.

Para descrição do ovo, foi utilizada a nomenclatura proposta por BeEBE et al. (1960), HinTON (1981) e DowneY \& Allyn (1981). As áreas do corpo da larva foram nomeadas segundo PETERSON (1962). A nomenclatura para as larvas de primeiro instar foi a de HinTon (1946) e Fleming (1960), modificada por Stehr (1987). Para os escolos seguiu-se BEEBE et al. (1960) e, para a terminologia das estruturas da pupa, Mosher (1916) e BEEBE et al. (1960).

\section{RESULTADOS E DISCUSSÃO}

Ovo (figs. 1 - 6). Coloração amarela a laranja-opaca, com manchas marrons, próximo à eclosão. Subcilíndrico achatado na porção apical, a base pode ser mais afilada que o ápice (fig. 1). Dimensões (média \pm erro padrão, $n=$ 
10): $1,190 \pm 0,018 \mathrm{~mm}$ e $0,873 \pm 0,012 \mathrm{~mm}$ para altura e diâmetro, respectivamente. Estes valores são similares aos encontrados por BEEBE et al. (1960) e BROWN (1981).

A distribuição das carenas na superfície do ovo (carenas horizontais, Hr; verticais, Vr) (fig. 1) delimita células que possuem os cantos internos arredondados. Células inferiores retangulares (fig. 3); no terço superior do ovo são pentagonais ou hexagonais (fig. 4) e reduzem numericamente em direção ao ápice. $\mathrm{O}$ número de $\mathrm{Vr}$ varia de 17 a 19 e as $\mathrm{Hr}$, de 10 a $12(n=10)$; estes valores são similares aos obtidos por BEEBE et al. (1960) e BROWN (1981). Cório liso (figs. 3, 4), semelhantes aos de Agraulis vanillae maculosa (Stichel, 1907), Dione juno juno (Cramer, 1779), Dryadula phaetusa (L., 1758), Philaethria wernickei (Röber, 1906) e diferente de Heliconius erato phyllis (Fabricius, 1775), o qual se apresenta coberto por
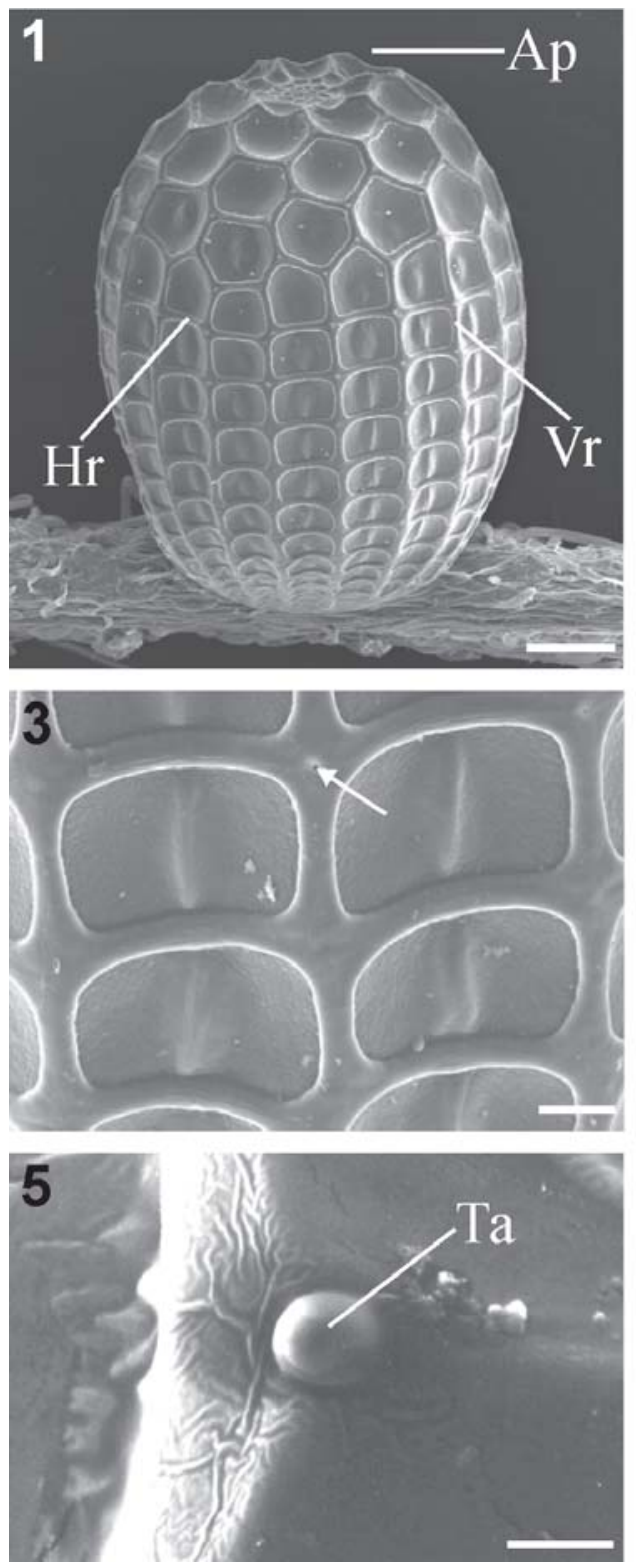

pequenas depressões (KAMINSKI et al., 2002; TAVARES et al., 2002). Região micropilar (fig. 2) levemente côncava, de formato irregular e subdividida em duas áreas, denominadas ânulo e roseta por Downey \& ALlyn (1981). Ânulo, porção mais externa da região micropilar, com células que variam em tamanho e forma. Roseta, localizada internamente ao ânulo, com células poligonais arranjadas em espiral que decrescem de tamanho em direção ao centro, onde se localizam as micrópilas (Mp, fig. 2). Aerópilas, como pequenas protuberâncias arredondadas (Ac, fig. 6), situadas nos vértices das carenas, aqui denominadas tampas das aerópilas (Ta, figs. 5, 6). Aerópilas, cobertas por tampas (fig. 5), decumbentes (fig. 6) ou ausentes (fig. 4), representadas nestes casos pelo peritrema e abertura correspondente. Nos gêneros de heliconíneos cuja ultraestrutura coriônica é conhecida
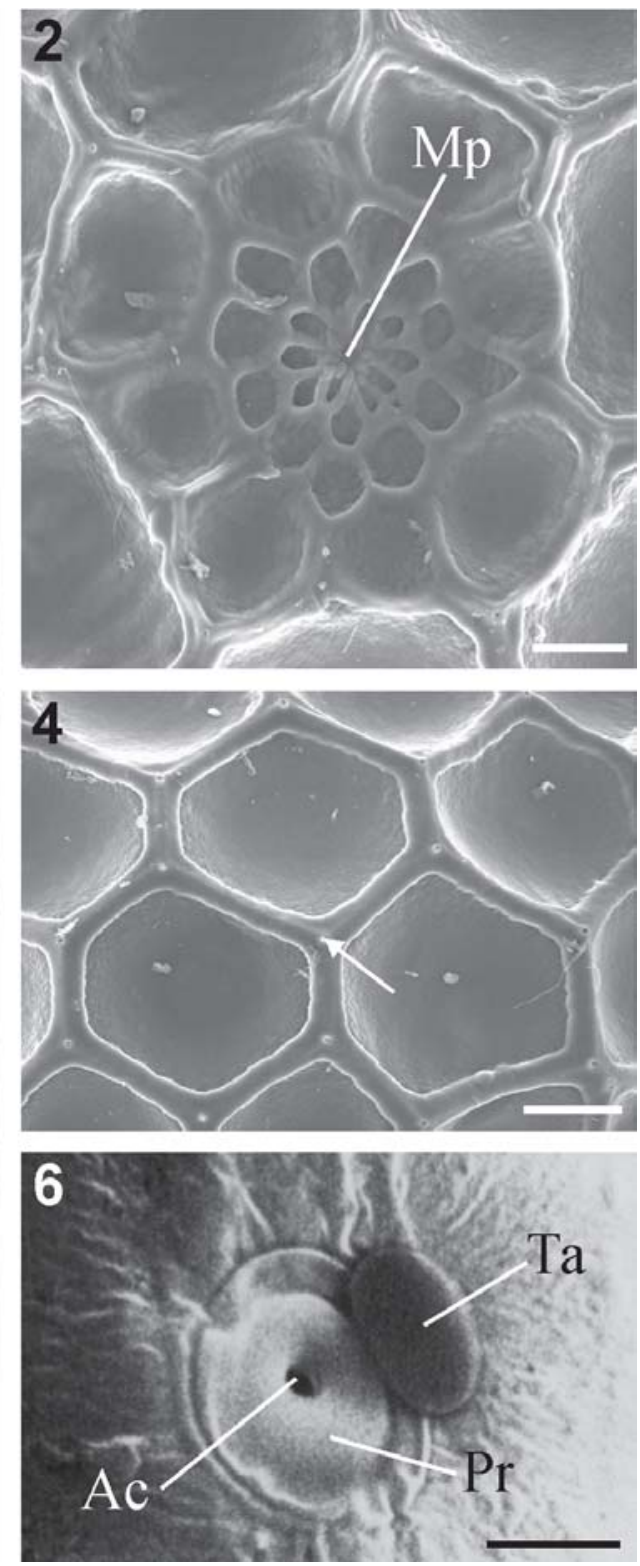

Figs. 1-6. Dryas iulia alcionea, ovo: 1, vista látero-dorsal; 2, região micropilar; 3, células inferiores; 4, células superiores; 5, aerópila com abertura encoberta; 6, aerópila com tampa decumbente (Ac, abertura da aerópila; Ap, pólo anterior; Hr, carena horizontal; Mp, micrópilas; Pr, peritrema; Ta, tampa da aerópila; Vr, carena vertical; setas indicam posição das aerópilas). Barras: fig. 1, $200 \mu \mathrm{m}$; figs. $2,3,50 \mu \mathrm{m}$; fig. $4,5 \mu \mathrm{m}$; fig. $5,10 \mu \mathrm{m}$; fig. $6,3 \mu \mathrm{m}$. 
(Agraulis Boisduval \& Leconte, 1836, Dione Hübner, 1818, Dryadula Michener, 1942, Eueides Hübner, 1816, Heliconius Kluk, 1802 e Philaethria Billberg, 1820), a abertura da aerópila é desprovida de tampa (ANTUNES et al., 2002; KAMINSKI et al., 2002; TAVARES et al., 2002).

Larva (figs. 7-23). Dryas iulia apresenta um dos padrões de coloração mais complexos e variáveis dentre as larvas de primeiro instar em Heliconiinae (BEEBE et al., 1960). Cápsula cefálica marrom-amarelada, restante do corpo um pouco mais claro. Conteúdo intestinal, visível por transparência após a alimentação, gerando uma faixa marrom-esverdeada. Manchas brancas e faixas marromescuras distribuídas pelo tórax e abdome. Cerdas da cápsula cefálica marrom-escuras na base e ápice translúcido. Cerdas do tórax e abdome pretas, com a base marrom-escura e porção terminal hialina.

Ao contrário do que ocorre em Eueides isabella dianasa (Hübner, 1806) e D. juno juno (ANTUNES et al., 2002; TAVARES et al., 2002), o anteclípeo (sensu MiLler, 1991) não é aparente, sendo semelhante ao descrito para
H. erato phyllis (KAMINSKi et al., 2002). Antena (fig. 11) constituída por três artículos: primeiro, curto e alargado; segundo, alongado com quatro sensilas, duas curtas e duas longas; terceiro, menor com quatro sensilas curtas. Antacória com protuberâncias semelhantes ao encontrado em $D$. juno juno (TAVAREs et al., 2002).

Quetotaxia da cápsula cefálica (fig. 7) com pouca variação, semelhante à obtida em outras espécies de heliconíneos (Fleming, 1960; Antunes et al., 2002; KAMINSKi et al., 2002; TAVARES et al., 2002). Em cada epicrânio, presentes as cerdas: P1, P2, L1, A1, A2, A3, AF1, AF2, S1, S2, SS2. As cerdas S3, SS1 e SS3 não são visíveis em vista frontal. Frontoclípeo com os pares de cerdas C1, C2 e F1. Cerdas menores no labro, maxila e mandíbula (STeHr, 1987; Miller \& Otero, 1994). Poros $\mathrm{Aa}, \mathrm{AFa}, \mathrm{La}, \mathrm{MDa}, \mathrm{Pa}, \mathrm{Pb}$ e $\mathrm{Sb}$ presentes, sendo que $\mathrm{MGa}, \mathrm{Sa}$ e SSa não são visíveis em vista frontal. Microcerdas MD1, MD2 e MD3 posteriores à cerda P2, com o poro MDa situado entre as microcerdas MD1 e MD2. A posição relativa desse poro difere do padrão
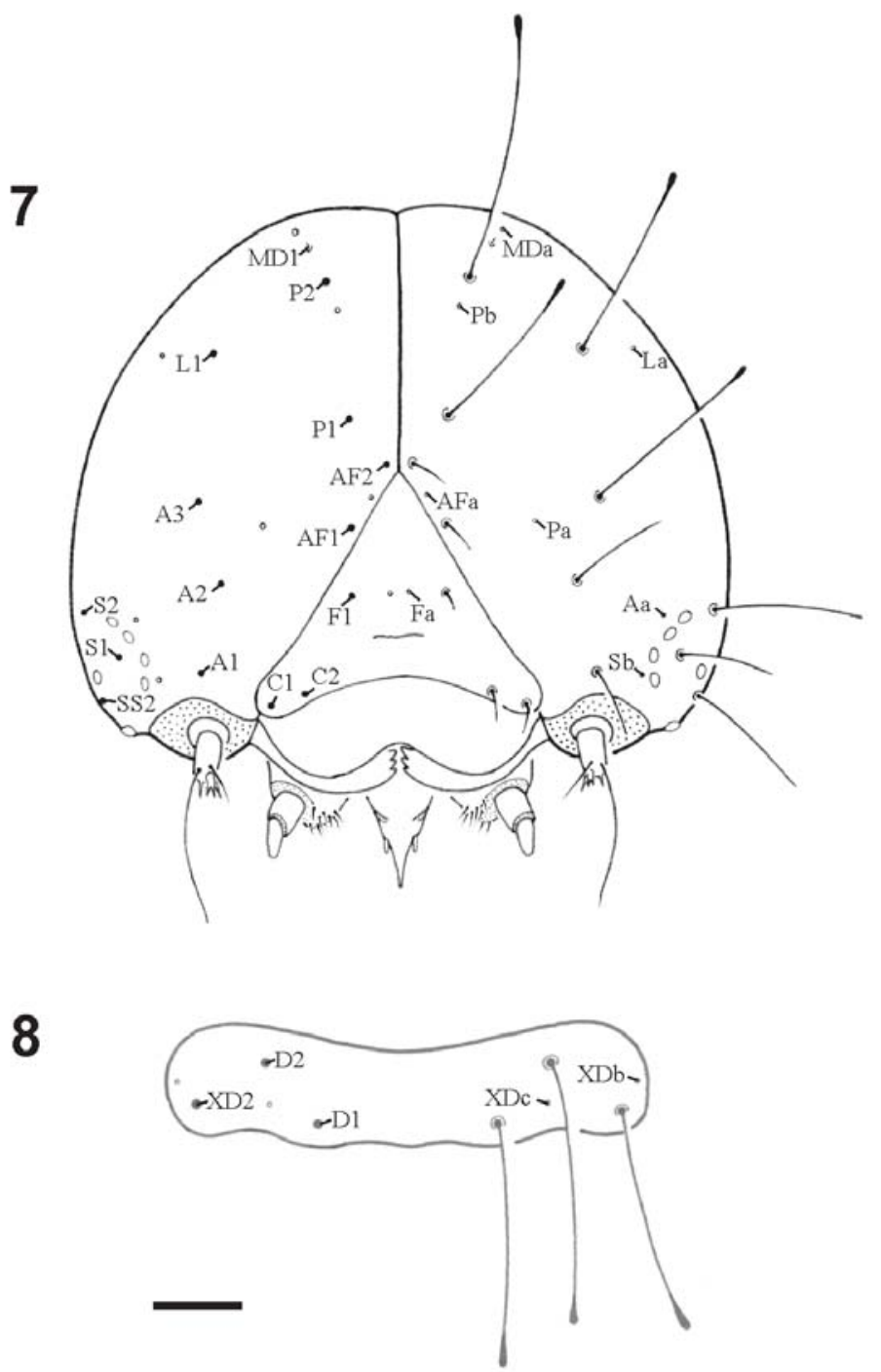

Figs. 7, 8. Dryas iulia alcionea, larva de primeiro instar: 7, cápsula cefálica, vista frontal; 8, placa protorácica, vista dorsal (A, cerda anterior; Aa, poro anterior; AF, cerda adfrontal; Afa, poro adfrontal; C, cerda clipeal; D, cerda dorsal; F, cerda frontal; Fa, poro frontal; L, cerda lateral; La, poro lateral; MD, microcerda dorsal; MDa, poro dorsal; P, cerda póstero-dorsal; Pa e Pb, poros pósterodorsais; S, cerda estematal; Sb, poro estematal; SS, cerda subestematal; XD, poros e cerdas protorácicas). Barra, $90 \mu \mathrm{m}$. 
geral para Lepidoptera (STEHR, 1987), conforme já descrito para outros Heliconiinae e Acraeinae (PALUCH et al., 2001; KAMinsKi et al., 2002; TAVARES et al., 2002). O grupo estematal é representado pelas cerdas $\mathrm{S} 1, \mathrm{~S} 2$, e S3. A cerda $\mathrm{S} 1$ localiza-se internamente ao semicírculo formado pelos estemas e próxima ao estema 6; S2 situada fora do semicírculo, próxima ao estema 1 e dorsalmente a S1; S3 lateralmente ao estema 6. Poro $\mathrm{Sb}$, associado aos estemas, entre os estemas 3 e 4. Cerdas subestematais (SS1, SS2, SS3) na área genal, abaixo dos estemas, são relativamente menores que as demais cerdas cefálicas.

Placa protorácica (fig. 8), com as cerdas D1, D2 e XD2. Segundo Fleming (1960), nela está o par de poros XDc. Foi observado outro par de poros situado ventralmente em relação à seta XD2, denominado XDb por Antunes et al. (2002). Além das cerdas da placa protorácica, encontram-se ainda: L1, L2, SD1, SD2, SV1 e SV2 (fig. 9). Mesotórax e metatórax semelhantes quanto à distribuição das cerdas. O grupo dorsal (fig. 9) é constituído pelas cerdas D1 e D2 em pináculas separadas, sendo a D1 maior e situada dorsalmente à cerda D2. Cerdas subdorsais localizadas sobre uma mesma pinácula. Grupo lateral representado pela cerda L1 e o grupo subventral, constituído pela cerda SV1, localizada dorsalmente à inserção da coxa.

Nas pernas, várias cerdas, destacando-se as tibiais e tarsais. Apesar da nomenclatura para as cerdas das pernas não ser de uso comum, as tarsais, presentes em todos os lepidópteros, possuem homologia bem determinada (Miller, 1991). Quatro cerdas tarsais: Ts1, Ts2, Ts3 e Ts4. Cerda Ts4, longa e curvada, semelhante a uma garra (Ga, fig. 12), excedendo a esta em tamanho.

Abdome com cerdas do grupo dorsal, subdorsal, lateral, subventral e ventral: o dorsal, cerdas D1 e D2 em todos os segmentos; o subdorsal, cerda SD1 do primeiro ao nono segmento abdominal, mais SD2 no décimo; o lateral, L1 e L2, ventralmente ao espiráculo. Cerdas laterais em pináculas independentes, sendo que L2 situada ântero-dorsalmente em relação à L1. O nono segmento não apresenta a cerda L2. Grupo subventral, cerda SV1 do primeiro ao nono segmento abdominal; do terceiro ao sexto, SV1 e SV2, inseridas na seção cilíndrica do larvópodo (SNODGRASS, 1935), que é incompleta, como em H. erato phyllis e D. juno juno (PENZ, 1999; KAMINSKI et al., 2002; TAVAREs et al., 2002). Grupo ventral constituído por cerdas curtas e finas (FLEMING, 1960); cerda V1 do primeiro ao nono segmento abdominal e a V2 no segundo e décimo.

Paraprocto com cerdas paraproctal (PP, fig. 9) e subparaproctal (sensu KITCHING, 1984; STEHR, 1987). Seção cilíndrica do larvópodo do décimo segmento abdominal, com cerdas PL1, PL2, PL3 e PL4. Distribuição e quantidade de cerdas para o décimo segmento abdominal, semelhantes ao descrito para Danainae (KiTching, 1984). As cerdas possuem a porção terminal dilatada, semelhante a uma clava (figs. 9, 13, 14), com exceção das cerdas menores, como as subventrais, ventrais e paraproctais. Cerdas dilatadas são encontradas em $H$. erato phyllis e Dione moneta moneta Hübner, 1825 (KAMINSKI et al., 2002). Em outros heliconíneos, a porção terminal das cerdas pode ser somente afilada, como em E. isabella dianasa, ou partida com três a quatro pontas,
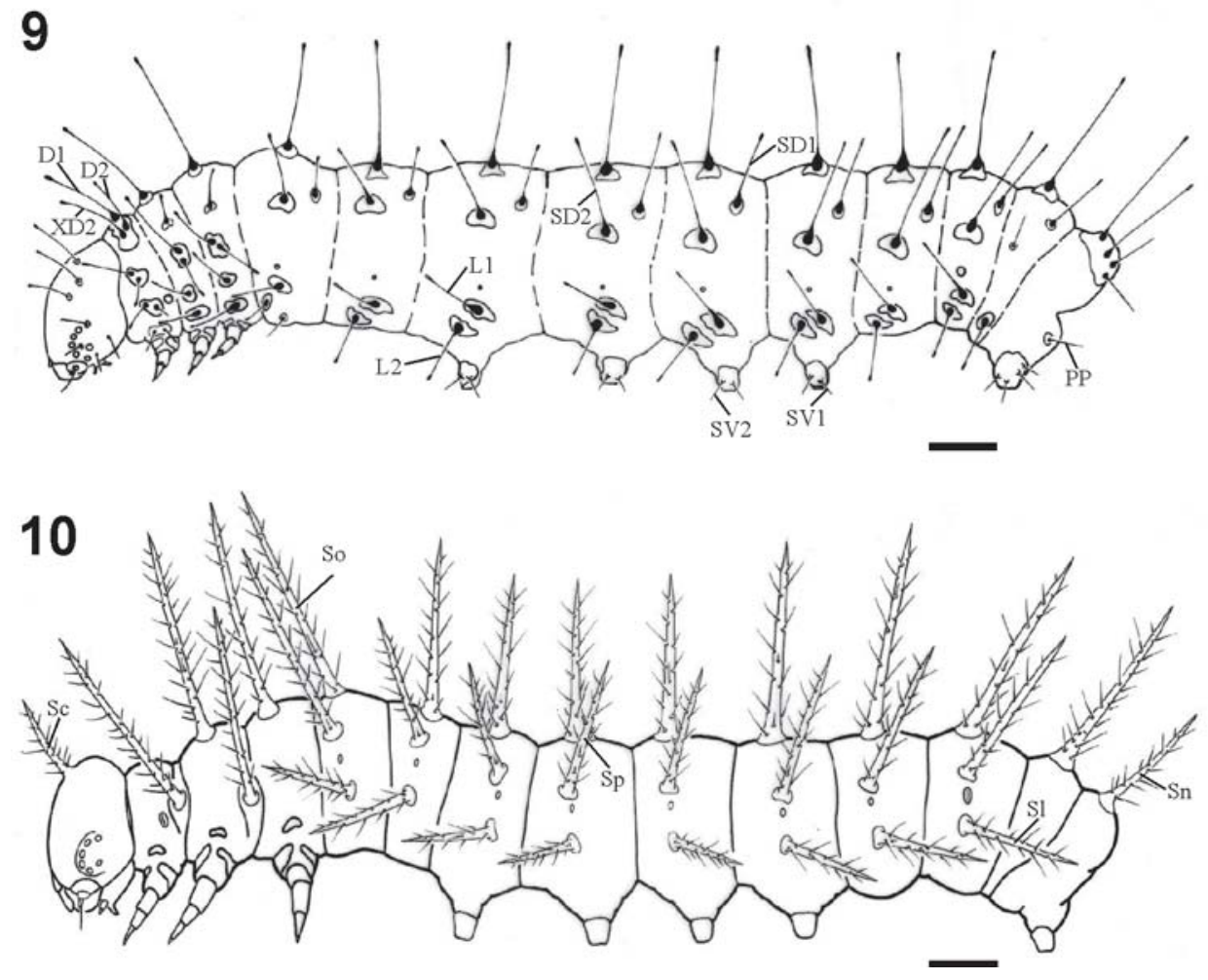

Figs. 9, 10. Dryas iulia alcionea, larvas em vista lateral: 9, primeiro instar; 10, quinto instar (D, cerda dorsal; L, cerda lateral; PP, cerda paraproctal; Sc, escolo cefálico; SD, cerda subdorsal; S1, escolo subespiracular; Sn, escolo anal; So, escolo dorsal; Sp, escolo supraespiracular; $\mathrm{SV}$, cerda subventral; XD, cerda protorácica). Barras: fig. 9, 0,2mm; fig. 10, $1 \mathrm{~mm}$. 
em D. juno juno (ANTUNES et al., 2002; TAVARES et al., 2002).

Tegumento coberto por microtríquias, concentradas na porção ventral e próximas aos larvópodos. Microtríquias cônicas e sem estrias, semelhantes àquelas encontradas em H. erato phyllis e D. juno juno (KAMINSKI et al., 2002; TAVARES et al., 2002). Espiráculos (fig. 15) com peritrema elevado e circular, o torácico e primeiro abdominal levemente maiores. Ganchos do larvópodo unisseriais e uniordinais, dispostos de forma circular na planta de cada larvópodo (fig. 16).

A partir do segundo instar surgem os escolos (figs. $10,17)$, cuja posição relativa permanece constante até o quinto instar. Apresentam projeções cuticulares com cerdas afiladas e quebradiças. Porção distal do escolo afilada, uma característica compartilhada entre os heliconíneos neotropicais estudados por PENZ (1999). Porção distal do escolo (fig. 18) na forma de uma cerda, semelhante à encontrada em $H$. erato phyllis (KAMINSKI et al., 2002), porém com a região de inserção bem delimitada.

Cápsula cefálica com um par de escolos desenvolvidos (Sc, fig. 10). O segmento protorácico é o mais conservado em relação às cerdas primárias. Mesotórax e metatórax com dois pares de escolos, um supraespiracular e um dorsal. Cerdas primárias substituídas por pináculas e escolos. Cerdas laterais, subventrais, e uma ventral em cada segmento. No primeiro ao oitavo segmentos abdominais, um par de
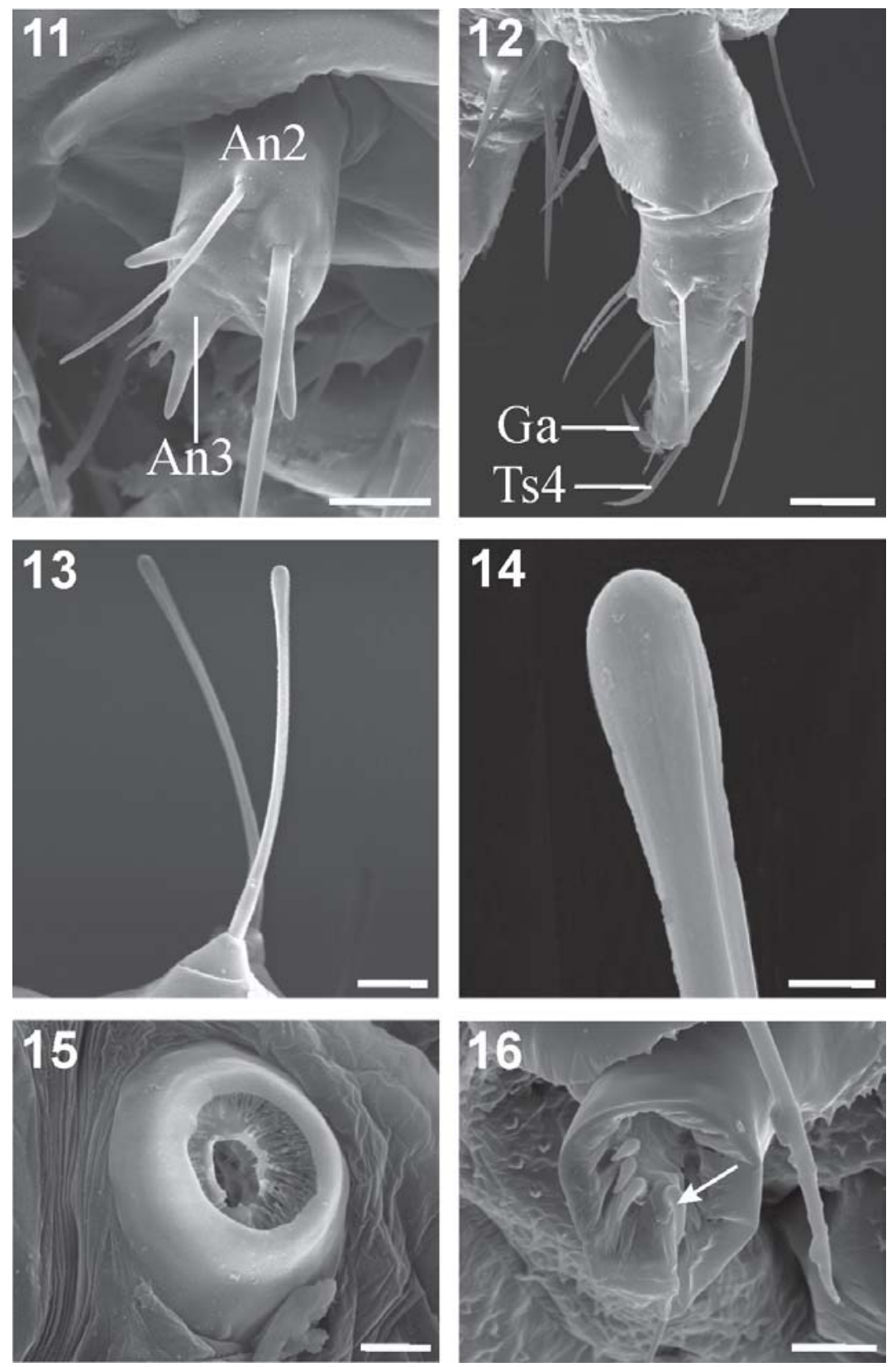

Figs. 11-16. Dryas iulia alcionea, larva de primeiro instar: 11, antena; 12, perna metatorácica; 13 , cerdas do tipo calaza, vista lateral; 14 , porção apical de uma cerda, vista lateral; 15, espiráculo do segundo segmento abdominal; 16, planta de um larvópodo, com ganchos expostos (seta) (An, artículo antenal; Ga, garra; Ts, seta tarsal). Barras: fig. 11, $20 \mu \mathrm{m}$; figs. 12,13, $50 \mu \mathrm{m}$; figs. 14,15, $10 \mu \mathrm{m}$; fig. 16, $20 \mu \mathrm{m}$. 
escolos subespiraculares. Nono e décimo segmentos abdominais, com apenas um par de escolos dorsais, denominado de escolos anais ( $\mathrm{Sn}$ ) no último.

Escolos dorsais e supraespiraculares (figs. 10, 23) dos segmentos mesotorácico, metatorácico e primeiro abdominal, levemente maiores que os demais, cerca de um terço, convergentes entre si e inclinados anteriormente. $\mathrm{O}$ mesmo padrão é observado entre os escolos dorsais do sétimo ao nono segmentos abdominais, porém inclinados posteriormente. O tamanho relativo dos escolos somado à leve curvatura da região torácica proporciona um aspecto geral típico para o gênero Dryas Hübner, 1807. Esta característica é mais evidente quando a larva encontra-se em posição de repouso (AleXANDER, 1961).
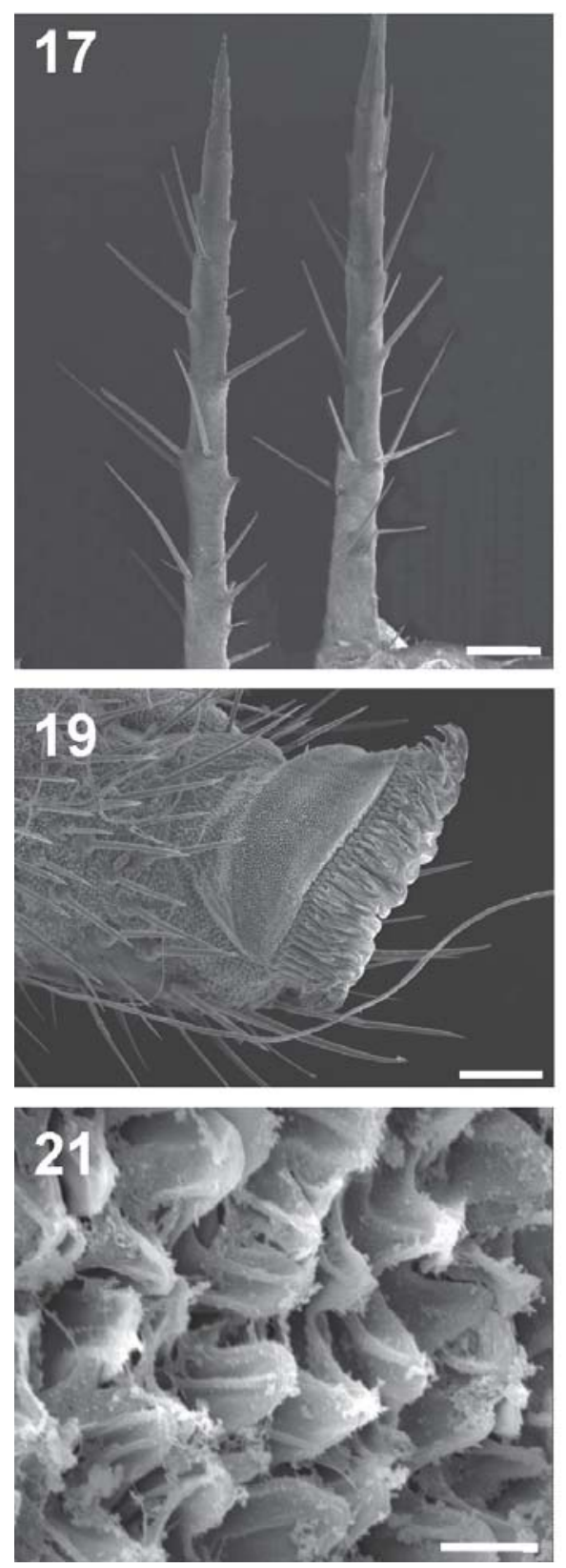

Padrão geral de coloração da larva de quinto instar (fig. 23) complexo e variável (BEEBE et al., 1960). A cápsula cefálica possui coloração de fundo branco com o frontoclípeo preto, uma faixa preta que se estende do escolo cefálico até a inserção da antena e região occipital bordô-escura. Área ventral do corpo preta. Área subespiracular branca, com estreitas faixas diagonais bordô-escuras. Áreas supraespiracular e dorsal com fundo cinza-amarronzado intercalado por faixas transversais brancas e pretas. O padrão descrito forma uma série de quatro faixas diagonais brancas (fig. 23).

No quinto instar, tegumento coberto por microtríquias (fig. 21) cônicas com estrias. Na região ventral do abdome, microtríquias com ápice afilado (PENZ, 1999); em outras regiões pode ser rombudo (fig. 21).
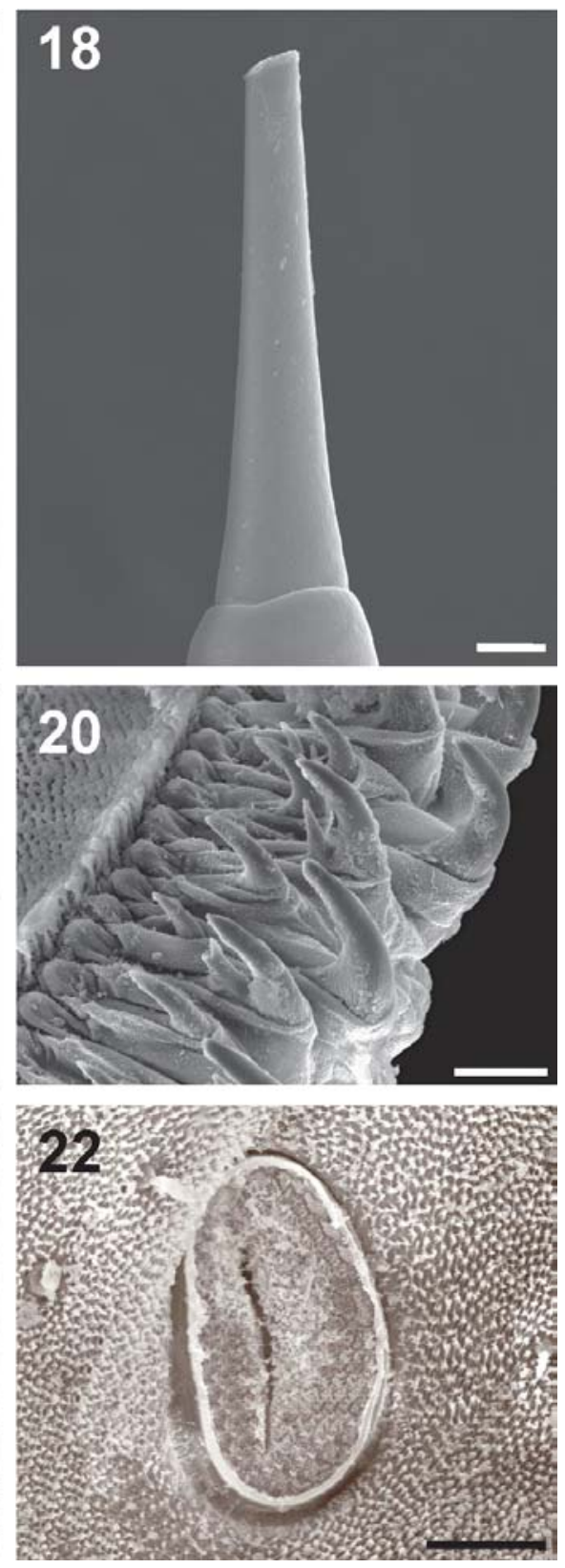

Figs 17-22. Dryas iulia alcionea, larva de quinto instar: 17, escolos; 18, porção terminal de um escolo; 19, planta de um larvópodo com ganchos; 20, detalhe dos ganchos do larvópodo; 21, microtríquias tegumentares; 22, espiráculo abdominal. Barras: fig. 17, 500 $\mu$ m; fig. $18,20 \mu \mathrm{m}$; fig. $19,200 \mu \mathrm{m}$; fig. $20,35 \mu \mathrm{m}$; fig. $21,10 \mu \mathrm{m}$; fig. $22,100 \mu \mathrm{m}$. 

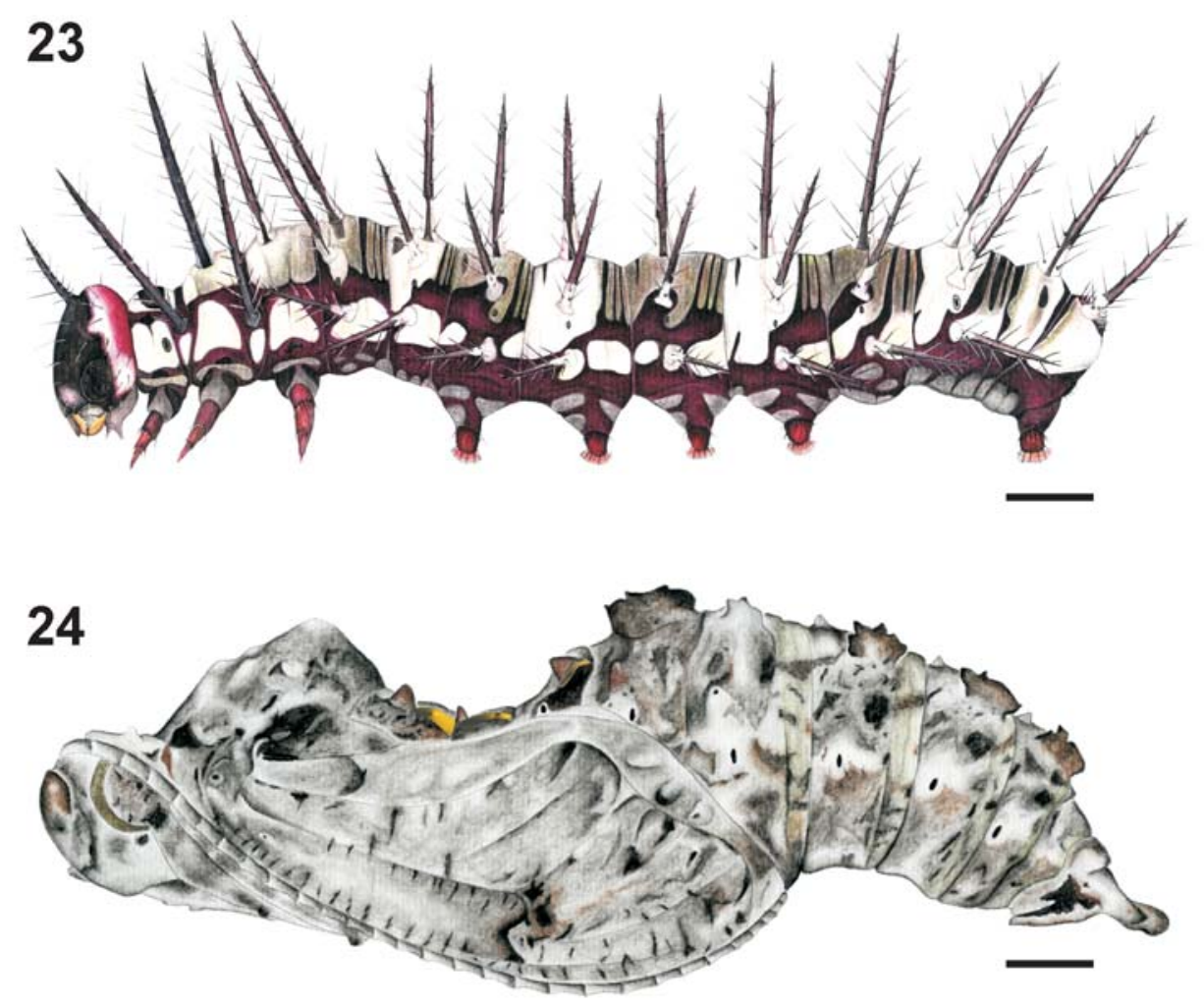

Figs. 23, 24. Dryas iulia alcionea, padrão de coloração: 23, larva de quinto instar; 24, pupa. Barras: fig. 23, 1mm; fig. 24, 2,2mm.

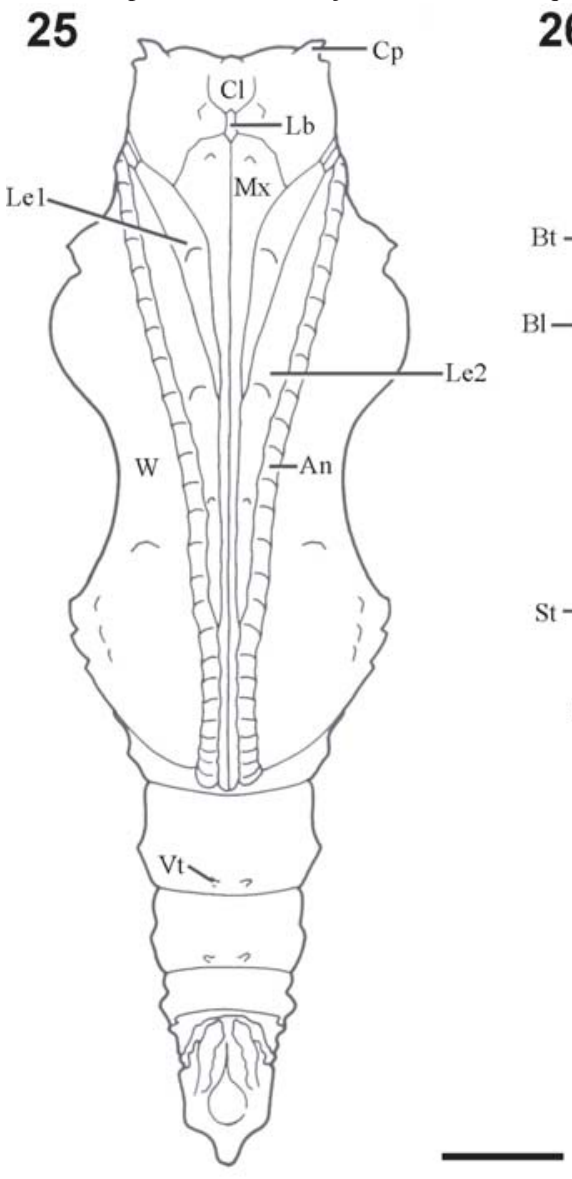

26
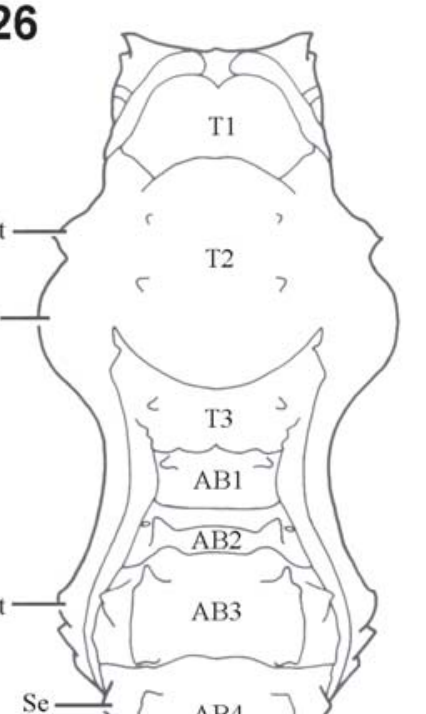

$\mathrm{Se}$

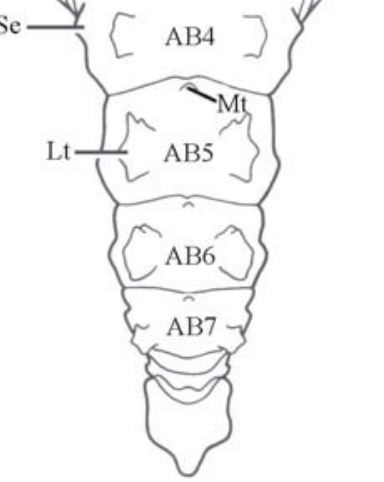

Figs. 25, 26. Dryas iulia alcionea, pupa: 25, vista ventral; 26, vista dorsal (AB, segmento abdominal; An, antena; B1, crista longitudinal; Bt, tubérculo basilar; Cl, clípeo; Cp, projeção cefálica; Lb, labro; Le1, perna protorácica; Le2, perna mesotorácica; Lt, tubérculo látero-dorsal; Mt, tubérculo médio-dorsal; Mx, máxila; Se, tubérculo supra-espiracular; St, tubérculo submarginal; T, segmento torácico; Vt, tubérculo ventral; $\mathrm{W}$, asa). Barra, 1,8 mm. 
Ganchos dos larvópodos (figs. 19, 20) unisseriais e triordinais. Espiráculos (fig. 22) elípticos, com peritrema pouco elevado em relação aos espiráculos do primeiro instar larval.

Identificação dos ínstares. Dryas iulia alcionea não apresenta variações conspícuas nas estruturas e no padrão de coloração, que possibilitem a identificação com precisão dos ínstares intermediários. A partir das medidas da largura da cápsula cefálica para as larvas criadas em laboratório (tab. I), obteve-se a seguinte equação de crescimento: $\ln y=0,41 \mathrm{x}-0,921 ; \mathrm{n}=105 ; \mathrm{r}=0,996 ; \mathrm{p}=$ 0,0001 . A razão média de crescimento da cápsula cefálica dentre os ínstares equivale a 1,50. Este valor é similar ao obtido para outros heliconíneos estudados (ANTUNES et
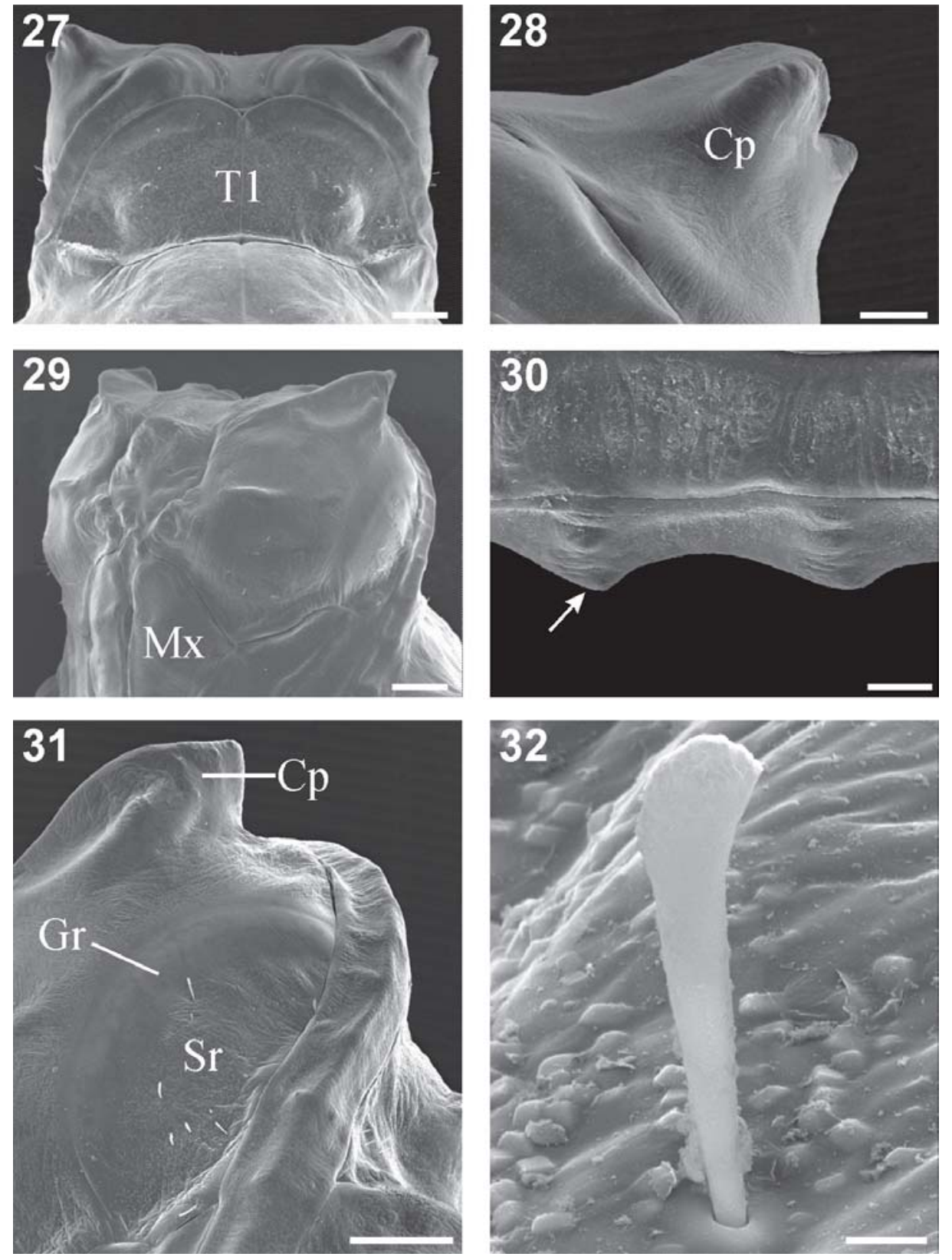

Figs. 27-32. Dryas iulia alcionea, pupa: 27, cabeça e protórax, vista dorsal; 28, projeção cefálica, vista dorsal; 29, cabeça, vista láterodorsal; 30, porção mediana da antena, vista lateral, com tubérculos (seta); 31, cabeça, vista lateral; 32, detalhe de uma cerda da região ocular (Cp, projeção cefálica; Gr, faixa de aspecto reluzente do olho; Mx, porção proximal da maxila; Sr, porção esculturada do olho; T, segmento torácico). Barras: figs. 27,29,30, $500 \mu \mathrm{m}$; fig. 28, $20 \mu \mathrm{m}$; fig. 31, $200 \mu \mathrm{m}$; fig. 32, $10 \mu \mathrm{m}$. 
al., 2002; KAMINSKi et al., 2002; TAVARES et al., 2002). Os intervalos de variação obtidos demonstraram que não há sobreposição da largura dentre os ínstares. Os dados ajustaram-se a uma equação exponencial, sugerindo crescimento segundo progressão geométrica. O padrão de crescimento da cápsula cefálica de $D$. iulia alcionea segue a regra de Brooks-Dyar, o que possibilita a identificação dos ínstares com precisão, conforme DALY (1985) observou para diversas espécies de lepidópteros.

Pupa (figs. 24-44). Dryas iulia alcionea segue o padrão geral proposto por Mosher (1916) para os Nymphalidae, no qual falta a sutura epicranial. Coloração da pupa não é uniforme, sendo constituída por diversas tonalidades de marrom com áreas claras entremeadas por regiões cinzas (fig. 24). Ocorrem variações na intensidade e nos detalhes dos desenhos entre indivíduos. Pares de manchas douradas, dorsais, no terceiro segmento torácico e no primeiro e segundo segmentos abdominais (fig. 24).

A região ocular pode ser dividida em duas áreas: uma de aspecto liso (Gr, fig. 31), e outra corrugada com cerdas (Sr, figs. 31,32) com a porção terminal dilatada, semelhante àquelas do primeiro instar. Este tipo de cerda também foi encontrado em pupas de $D$. juno juno, $E$. isabella dianasa e H. erato phyllis (ANTUNES et al., 2002; KAMINSKI et al., 2002; TAVARES et al., 2002). As mandíbulas localizam-se ventralmente. Entre estas, situa-se o labro (Lb, fig. 25) e, anteriormente a este, o clípeo ( $\mathrm{Cl}$, fig. 25). Posteriormente a estas estruturas estão as maxilas (Mx, figs. 25, 29), que se estendem até a porção distal das antenas (fig. 31). Lateralmente à maxila, situam-se o primeiro e o segundo par de pernas (Le1, Le2, fig. 25). As pernas protorácicas são menores que as mesotorácicas e ambas apresentam tubérculos (figs. 25, 35). As pernas
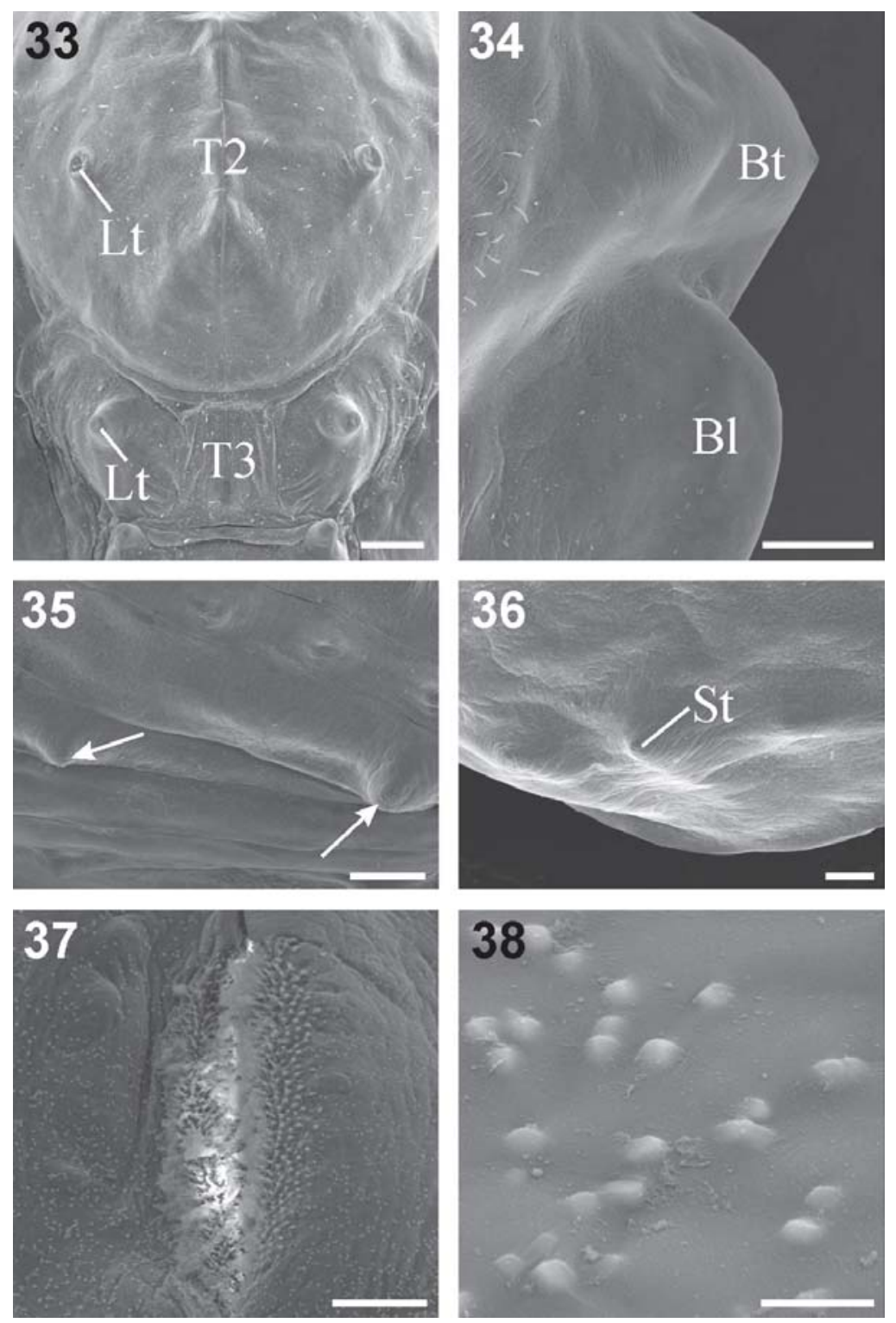

Figs. 33-38. Dryas iulia alcionea, pupa: 33, segmentos torácicos, vista dorsal; 34, porção proximal da asa anterior, vista dorsal; 35, tubérculos da perna protorácica e mesotorácica, vista ventral (setas); 36, asa, vista lateral; 37, espiráculo mesotorácico; 38, detalhe das ornamentações do tegumento (B1, crista longitudinal; Bt, tubérculo basilar; Lt, tubérculo lateral; St, tubérculo pós-mediano; T, segmento torácico). Barras: figs. 33-35, $500 \mu \mathrm{m}$; fig. 36, $200 \mu \mathrm{m}$; fig. 37, $100 \mu \mathrm{m}$; fig. $38,10 \mu \mathrm{m}$. 
metatorácicas são totalmente encobertas pelas asas, diferente de E. isabella dianasa que apresenta a porção distal da perna visível (ANTUNEs et al., 2002).

Par de projeções cefálicas curto (Cp, figs. 25, 28, 31), semelhante ao descrito por BEEBE et al. (1960) e BROwN (1981). Projeções lisas e cônicas, achatadas lateralmente e divididas em dois ramos (figs. 27, 31). Este padrão é diferente de $D$. juno juno, que apresenta projeções curtas, porém com superfície corrugada e repleta de protuberâncias (TAVARES et al., 2002).

Antenas entre as pernas mesotorácicas e as asas anteriores (fig. 25). A área correspondente à antena tem pequenos tubérculos (fig. 30), semelhantes aos encontrados em $D$. juno juno (TAVAREs et al., 2002), porém menos pronunciados.

$\mathrm{Na}$ base das asas anteriores (fig. 34), crista longitudinal $(\mathrm{Bl})$ e tubérculo basilar $(\mathrm{Bt})$. Na margem externa da asa anterior, três tubérculos submarginais e
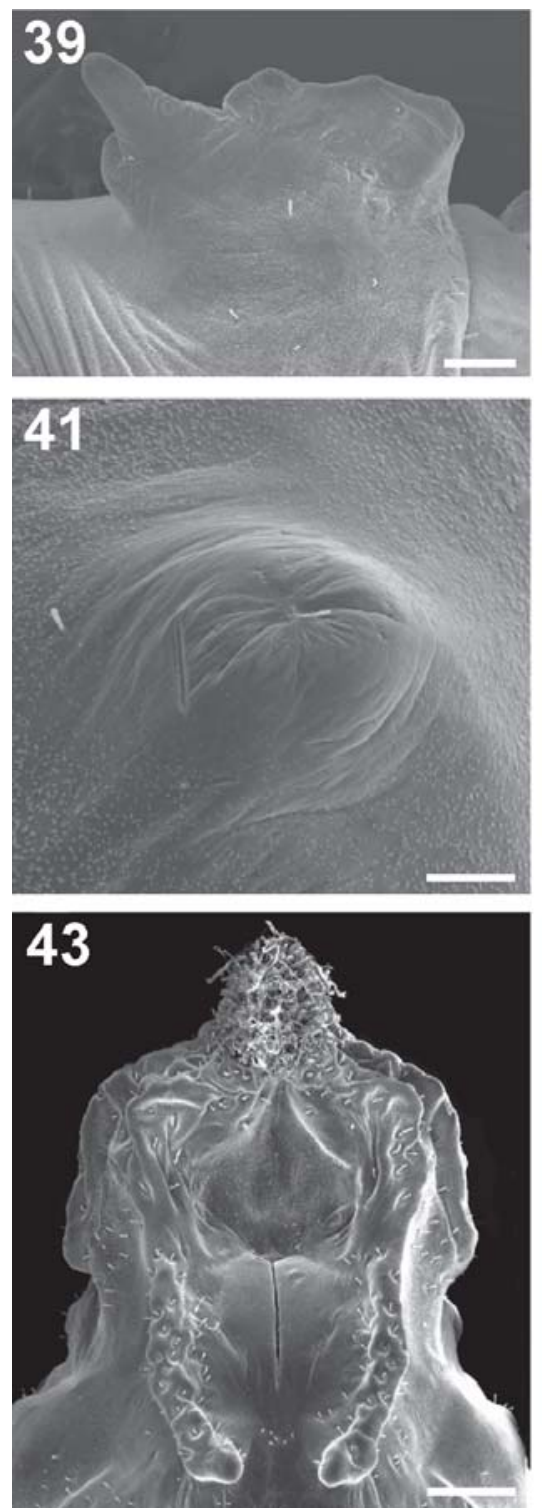

os três pós-medianos pouco pronunciados (St, fig. 36). Uma elevação localizada na parte central da asa, na borda distal da célula discal.

Dorsalmente três linhas de tubérculos (fig. 26): uma médio-dorsal e um par de látero-dorsais. Os tubérculos médio-dorsais (fig. 40), pouco proeminentes, no quinto e sexto segmentos abdominais. Os látero-dorsais (figs. 26, $33,39)$ presentes do mesotórax ao sétimo segmento abdominal; do terceiro ao sétimo abdominal, os láterodorsais são alargados na base, formando flanges (sensu BEEBE et al., 1960), não fusionadas e sem projeções espinhosas, como encontradas em $H$. erato phyllis (KAMinski et al., 2002). Tubérculos supraespiraculares pouco desenvolvidos (fig. 41). Linha de tubérculos ventrais ( $\mathrm{Vt}$, fig. 25) pouco pronunciada. Em geral, tegumento da pupa recoberto por ornamentações semelhantes a protuberâncias arredondadas, aleatoriamente distribuídas na superfície (fig. 38). Esta
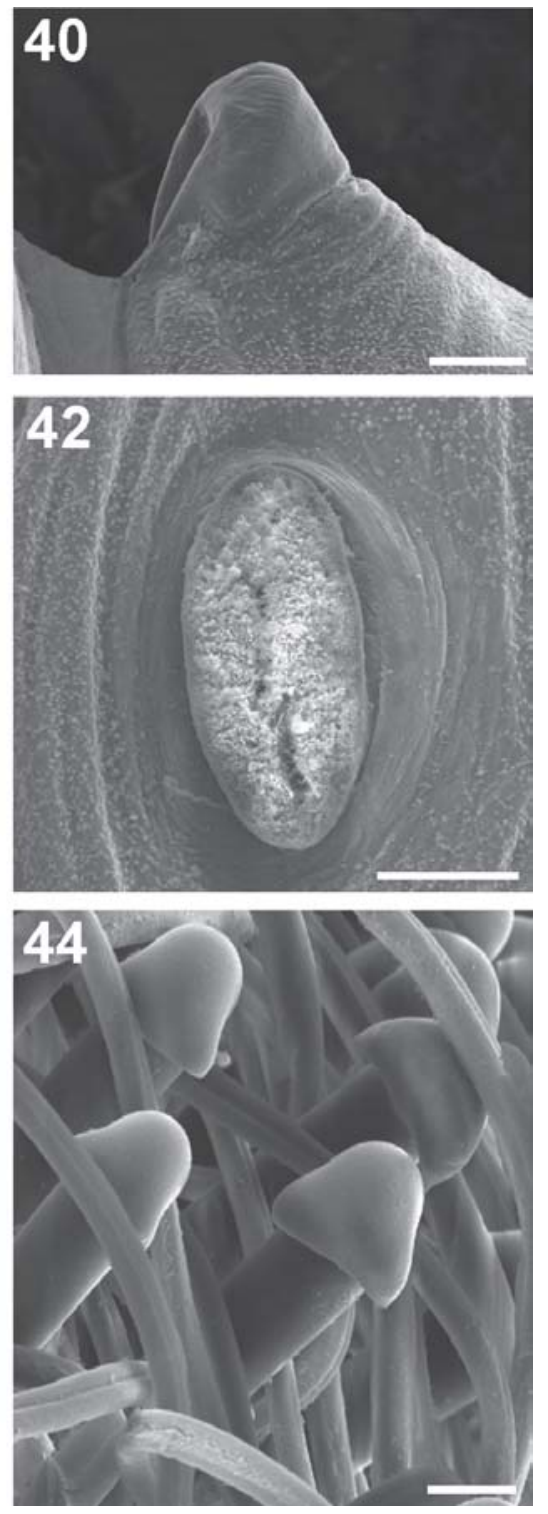

Figs. 39-44. Dryas iulia alcionea, pupa: 39, tubérculo lateral do quarto segmento abdominal, vista lateral; 40, tubérculo médio-dorsal do sexto segmento abdominal, vista lateral; 41, tubérculo supraespiracular; 42, espiráculo do quinto segmento abdominal; 43, cremáster, vista ventral; 44, ganchos do cremáster. Barras: fig. 39, $200 \mu \mathrm{m}$; figs. 40-42, $100 \mu \mathrm{m}$; fig. 43, 500 $\mu \mathrm{m}$; fig. 44, $20 \mu \mathrm{m}$. 
ornamentação também é encontrada em E. isabella dianasa (ANTUNES et al., 2002).

Abertura do espiráculo mesotorácico (fig. 37) em formato de fenda, situa-se na junção entre os segmentos pro- e mesotorácico. Demais espiráculos elípticos (fig. 42). Espiráculo do sétimo segmento abdominal, vestigial, sem uma abertura distinta como descrito para Lepidoptera (Mosher, 1916). Cremáster (fig. 43) retangular, achatado ventralmente, com inúmeros ganchos (fig. 44) alargados e recurvados, semelhantes ao obtido para outras espécies de heliconíneos (ANTUNEs et al., 2002; KAMINSKI et al., 2002; TAVARES et al., 2002).

Agradecimentos. Ao Centro de Microscopia Eletrônica (UFRGS), especialmente a Moema Queiroz Vieira, Francis Farret Darsie e Miriam Souza dos Santos pelo auxílio na preparação das amostras e realização das fotos. À Mônica Fagundes Acioli (LMCI) e ao Rafael Dell'Erba (UNEMAT), pelo auxílio nas micrografias e leituras críticas, respectivamente. Ao PIBIC/CNPq pela cota de bolsa de Iniciação Científica concedida a G. R. P. Moreira.

Este trabalho foi parcialmente financiado pelo $\mathrm{CNPq}$ (Processo no 478787/2001-4)

\section{REFERÊNCIAS BIBLIOGRÁFICAS}

AlexAnder, A. J. 1961. A study of the biology and behavior of the caterpillars, pupae and emerging butterflies of the subfamily Heliconiinae in Trinidad, West Indies. Part I. Some aspects of larval behavior. Zoologica, New York, 46:1-24.

Antunes, F. F.; Menezes, A. O., JR. et al. 2002. Morfologia externa dos estágios imaturos de heliconíneos neotropicais: I. Eueides isabella dianasa (Hübner, 1806). Revista Brasileira de Entomologia, Curitiba, 46(4):601-610.

Beebe, W.; Crane, J. \& Fleming, H. 1960. A comparison of eggs, larvae and pupae in fourteen species of heliconiine butterflies from Trinidad, W. I. Zoologica, New York, 45:111-154.

Benson, W. W.; Brown, K. S., JR. \& Gilbert, L. E. 1976. Coevolution of plants and herbivores: passion flowers butterflies. Evolution, Bolder, 29:659-680.

Brower, A. V. Z. \& Egan, M. G. 1997. Cladistic analysis of Heliconius butterflies and relatives (Nymphalidae: Heliconiiti): a revised phylogenetic position for Eueides based on sequences from mtDNA and nuclear gene. Proceedings of the Royal Society of London, Series B, London, 264:969-977.

Brown, K. S., JR. 1981. The biology of Heliconius and related genera. Annual Review of Entomology, Stanford, 26:427456.

1992. Borboletas da Serra do Japi: diversidade, hábitats, recursos alimentares e variação temporal. In: Morellato, L. P. C. org. História Natural da Serra do Japi: ecologia e preservação de uma área florestal no sudeste do Brasil. Campinas, Unicamp/Fapesp. p.142-187.

Brown, K. S., JR. \& Mielke, O. H. H. 1972. The heliconians of Brazil (Lepidoptera: Nymphalidae). Part II. Introduction and general comments, with a supplementary revision of the tribe. Zoologica, New York, 57:1-40.

Brown, K. S., JR. \& YePEZ, F. F. 1984. Los Heliconiini (Lepidoptera, Nymphalidae) de Venezuela. Boletín de Entomología Venezolana, Caracas, 3:29-76.

Daly, H. V. 1985. Insect morphometrics. Annual Review of Entomology, Stanford, 30:415-438.
De VRIES, P. J. 1987. The butterflies of Costa Rica and their natural history: Papilionidae, Pieridae, Nymphalidae. Princeton, Princeton University. 327p.

Downey, J. C. \& Allyn, A. C., JR. 1981. Chorionic sculpturing in eggs of Lycaenidae. Part I. Bulletin of the Allyn Museum, Gainesville, 61:1-29.

Emsley, M. G. 1963. A morphological study of imagine Heliconiinae (Lepidoptera: Nymphalidae) with a consideration of the evolutionary relationships within the group. Zoologica, New York, 48:85-130.

Fleming, H. 1960. The first instar larvae of the Heliconiinae (Butterflies) of Trinidad, W. I. Zoologica, New York, 45:91-110.

Hinton, H. E. 1946. On the homology and nomenclature of the setae of lepidopteran larvae, with some notes on the phylogeny of the Lepidoptera. Transactions of the Royal Entomological Society of London, London, 97:1-37.

. 1981. Biology of insect eggs. London, Pergamon. 473p.

Kaminski, L. A.; Tavares, M. et al. 2002. Morfologia externa dos estágios imaturos de heliconíneos neotropicais. III. Heliconius erato phyllis (Fabricius) (Lepidoptera, Nymphalidae, Heliconiinae). Revista Brasileira de Zoologia, Curitiba, 19(4):977-993.

Kitching, I. J. 1984. The use of larval chaetotaxy in butterfly systematics, with special reference to the Danaini (Lepidoptera: Nymphalidae). Systematic Entomology, Oxford, 9:49-61.

LeE, C. S.; McCool, B. A. et al. 1992. Phylogenetic study of heliconiine butterflies based on morphology and restriction analysis of ribosomal RNA genes. Zoological Journal of the Linnean Society, London, 106:17-31.

Miller, J. S. 1991. Cladistics and classification of the Notodontidae (Lepidoptera: Noctuoidea) based on larval and adult morphology. Bulletin of the American Museum of Natural History, New York, 204:1-230.

Miller, J. S. \& Otero, L. D. 1994. Immature stages of Venezuelan Dioptinae (Notodontidae) in Josia and Thirmida. Journal of the Lepidopterists Society, Los Angeles, 48:338-372.

Mosher, E. 1916. A classification of the Lepidoptera based on characters of the pupa. Bulletin of the Illinois State Laboratory of Natural History, Urbana, 12:1-165.

Paluch, M.; Casagrande, M. M. \& Mielke, O. H. H. 2001. Estágios imaturos de Actinote carycina Jordan (Lepidoptera: Nymphalidae: Acraeinae). Revista Brasileira de Zoologia, Curitiba, 18(3):883-896.

Penz, C. M. 1999. Higher level phylogeny for the passion-vine butterflies (Nymphalidae: Heliconiinae) based on early stage and adult morphology. Zoological Journal of the Linnean Society, London, 127:277-344.

Périco, E. \& ARAúJo, A. M. 1991. Suitability of hosts plants (Passifloraceae) and their acceptableness by Heliconius erato and Dryas iulia (Lepidoptera: Nymphalidae). Evolución Biológica, Bogotá, 5:59-74.

Peterson, A. 1962. Larvae of insects. An introduction to Neartic species. Part I. Lepidoptera and plant infesting Hymenoptera. Ann Arbor, Edwards Brothers. 315p.

SNedeCor, G. W. \& Cochran, W. G. 1980. Statistical methods. Ames, Iowa State University. 507p.

SnOdgrass, R. E. 1935. Principles of insect morphology. New York, McGraw-Hill. 667p.

Stehr, F. W. 1987. Order Lepidoptera. In: Stehr, F. W. ed. Immature insects. Dubuque, Kendall/Hunt. v.1, p. 288-305.

Tavares, M.; Kaminski, L. A. \& Moreira, G. R. P. 2002. Morfologia externa dos estágios imaturos de heliconíneos neotropicais. II. Dione juno juno (Cramer) (Lepidoptera: Nymphalidae: Heliconiinae). Revista Brasileira de Zoologia, Curitiba, 19(4):961-976. 
